\title{
Differences among Men and Women with Schizophrenia: A Study of US and Indian Samples
}

\author{
Pramod Thomas ${ }^{1,2}$ \\ Joel Wood ${ }^{2}$ \\ Abha Chandra ${ }^{3}$ \\ Vishwajit L Nimgaonkar ${ }^{2,4}$ \\ Smita N Deshpande ${ }^{1,5}$ \\ ${ }^{1}$ Training Program for Psychiatric \\ Genetics in India, \\ Department of Psychiatry, \\ PGIMER-Dr. Ram Manohar \\ Lohia Hospital, \\ Delhi, India \\ ${ }^{2}$ Department of Psychiatry, \\ University of Pittsburgh \\ School of Medicine Pittsburgh, PA \\ ${ }^{3}$ Department of Statistics, \\ Meerut College, Meerut, UP \\ ${ }^{4}$ Department of Human Genetics, \\ University of Pittsburgh \\ School of Medicine, Pittsburgh, \\ PA, USA \\ ${ }^{5}$ Department of Psychiatry, \\ PGIMER-Dr. Ram Manohar \\ Lohia Hospital, Delhi, India
}

\section{$\triangle$ Correspondence}

Smita N Deshpande, MD, DPM

Associate Prof. of Psychiatry \& Head,

Department of Psychiatry,

PGIMER-Dr. Ram Manohar

Lohia Hospital,

New Delhi-110001, India

Tel +91-11-23404363

Fax +91-11-23342122

E-mail smitadeshp@gmail.com indusszgenes@gmail.com

(c) This is an Open Access article distributed under the terms of the Creative Commons Attribution Non-Commercial License (http://creativecommons.org/licenses/by-nc/3.0) which permits unrestricted non-commercial use, distribution, and reproduction in any medium, provided the original work is properly cited.
Objective To test the hypothesis that similar differences in psychopathology are present across cultures among men and women with schizophrenia (SZ).

Methods Sex based differences were tested systematically in two independent samples from the Northeastern USA and North India using the same procedures. The clinical variables were obtained from five interview instruments.

Results Among the US participants, the number of significant differences exceeded chance predictions $(15 / 240$ variables significant at $p<0.02,6.25 \%$; expected number of significant differences: 5). Similarly, a greater than expected number of variables differed significantly between men and women among the Indian subjects (13/230 differences at $p<0.02,5.65 \%$; expected: 5). One of these variables significantly differed in both samples (lifetime abuse of cannabis). When multivariate analyses were conducted in the combined US and Indian samples sex based differences remained for only four variables: course of the illness, history of inappropriate emotions, marital status and number of children.

Conclusion Sex based differences in SZ/schizoaffective disorder are present in the USA and India at greater than chance probabilities. The majority of the variables differ across the samples. The biological underpinnings of these variables need further investigation.

Psychiatry Investig 2010;7:9-16

Key Words Schizophrenia, Gender, Sex, Psychopathology, Cross-cultural.

Received: January 15, 2010 Revised: February 23, 2010 Accepted: February 24, 2010

Available online: March 10, 2010

\section{Introduction}

There has been extensive interest in sex differences in schizophrenia (SZ). The research runs the gamut from large scale epidemiological studies to smaller studies describing diagnostic and clinical differences. Some studies, including meta-analyses, suggest a modest increase in the incidence and prevalence of SZ among men. ${ }^{1-3}$ More substantive differences in clinical features, particularly severity have been documented repeatedly. Women with SZ report affective symptoms, auditory hallucinations and persecutory delusions more frequently, with lower prevalence of smoking and substance abuse. ${ }^{4}$ These authors also reported that male patients had more negative symptoms and cognitive deficits. Though a prospective, double blind placebo controlled trial comparing 24 male and 20 female patients did not find significant sex-based differences, ${ }^{5}$ an extensive review suggested that optimal antipsychotic maintenance regimens differ between women and men. ${ }^{6}$ A review of 76 studies on tardive dyskinesia (TD), published through 1989 suggested a significantly higher prevalence in women $(26.6 \%)$ than in men $(21.6 \%)$, with a tendency for more severe TD among women.

There is substantial evidence that men with SZ suffer a more severe form of the illness and a more malignant course than women. ${ }^{8}$ Women also have significantly better social function. ${ }^{4,9-11}$ Men are more likely to have an earlier age at onset, a variable correlated with more severe illness. ${ }^{12-14}$ Sex significantly influenced global measures of function in a two year follow-up of 200 patients. ${ }^{15}$ A systematic meta-analysis of twenty three studies detected a high- 
ly significant association between male sex and deficit SZ [pooled odds ratio $(\mathrm{OR})=1.75] .{ }^{16}$ Women with $\mathrm{SZ}$ exhibited a less deteriorated course of illness. ${ }^{17}$ Not all studies have consistently reported a more severe form of illness among men. ${ }^{11}$ Ten year follow up of 141 first admitted patients and patients with schizophreniform disorder reported no significant difference between men and women in clinical outcome. ${ }^{18}$ Other conflicting results have also been reported. ${ }^{19,20}$ These differences likely reflect the heterogeneity of presentation of SZ, the likely impact of sample size variation and even subtle diagnostic differences. ${ }^{21}$

Under the assumption that the sex differences reflect the impact of factors that are inherent to the disorder, many investigators have explored biological factors. Some studies have revealed differences in imaging variables ${ }^{22,23}$ as well as chromosome related differences. ${ }^{24}$ The most extensive focus has been on hormonal differences, possibly related to dopamine dysfunction. . $^{14,25-28}$

It has been suggested that the later onset among women may be related to a protective effect of estrogens. ${ }^{28}$ Convincing biological explanations for sex related clinical differences have not been obtained, possibly because such explanations do not take into account diverse influences, including social variables. ${ }^{4,29-31}$

Almost all these data originate from Caucasian samples, but there is some evidence for ethnic variation with regard to these differences. For example, the well established sex difference in age at onset has not been detected in four studies from the Indian sub-continent. ${ }^{32-35}$ Another group found that Asian patients had lower prevalence of TD than North American, European, and African patients. ${ }^{7}$ Thus, cross-ethnic studies may provide additional insights into the sex differences in SZ.

We have analyzed differences among men and women in relation to clinical variation in two large independent samples, one recruited from north eastern USA and another from northern India. Both samples were recruited and evaluated using the same designs, enabling meaningful comparisons.

\section{Methods}

\section{Study design}

We aimed to identify variables with sex based differences that were consistent across the Indian and US samples. To reduce the likelihood of false positive results, analyses were conducted in two stages. In view of likely cross-national differences, we initially analyzed the samples separately using univariate analyses (Stage I). Only variables that remained significant following conservative Bonferoni corrections were retained for further analysis. These variables were used as dependent variables in multivariate analyses that included site as well as key demographic and clinical variables as covariates (Stage II).

\section{Variables used for analysis}

Patients with SZ or schizoaffective disorder were recruited from treatment facilities in US and India as described. ${ }^{36,37}$ The primary recruitment sites were Dr. Ram Manohar Lohia Hospital (RML), a publicly funded tertiary care center providing inpatient and outpatient care New Delhi, India and University of Pittsburgh, USA. Participants were sought among inpatients and outpatients at publicly funded hospitals and private clinics in both cities, so as to sample from the spectrum of care available at each site. Recruiters approached various psychiatrists in different private and public hospitals and requested the psychiatrists to refer willing persons with SZ or schizoaffective patients for the participation. The consented individuals were referred to us and after documenting informed consent, they were enrolled in to the study.

Briefly, potentially eligible patients diagnosed clinically with SZ or psychoses were interviewed using the English or the Hindi versions of the Diagnostic Interview for Genetic Studies (DIGS), a semi-structured interview schedule. ${ }^{38,39}$ The reliability of the English and the Hindi versions of the DIGS have been investigated. ${ }^{38,39}$ The DIGS includes sections covering different domains of psychopathology. Each section typically begins with screening questions that enable participants to 'skip out' if initial responses are negative. The following sections of the DIGS were completed routinely: Demographic details, Medical history, Overview of psychiatric illness, Major Depression, Mania/Hypomania, Dysthymia, Alcohol abuse and dependence, Drug abuse and dependence, Psychosis, Comorbidity assessment, Suicidal Behaviour. Onset age of psychosis was assessed in a standardized manner as described in question 64 of psychosis section of the DIGS, in India as well as in US. Additional scales that form part of the DIGS were also administered, namely the Global Assessment Scale, ${ }^{40}$ the Scale for Assessment of Negative symptoms, ${ }^{41}$ the Scale for Assessment of Positive Symptoms, ${ }^{42}$ Schizotypy Interview Schedule (SIS) ${ }^{43}$ and the OPCRIT. ${ }^{44}$ Information was also obtained from medical records, as well as from relatives and relevant clinicians. The information was synthesized and presented to board certified psychiatrists for consensus diagnosis. Inter-rater and inter-site diagnostic reliability was monitored throughout the study. All participants provided written informed consent, as required by the University of Pittsburgh Institutional Review Board and the Ethics Committee at Dr Ram Manohar Lohia Hospital, New Delhi.

\section{Statistical analysis}

Variables were compared using the chi-square test or the Student's t-test as appropriate. The Bonferroni correction was used to account for multiple comparisons. We further analysed such statistically significant variables, using logistic regression and multinomial regression. The Statistical Package 
for the Social Sciences versions 14 and 16 (SPSS 14, 16) were used for all analyses.

\section{Results}

\section{Stage I: Univariate analyses}

In view of 'skip outs' in different parts of the DIGS, the number of participants who responded to individual questions varied. A total of 635 records each with 240 variables from USA and 891 records with 230 variables from India were included for analysis.

The demographic variables and DSM-IV diagnoses for the participants are provided in Table 1 . There were 395 men in the US sample $(62.2 \%)$ and 488 men in the Indian sample (54.8\%). The mean age of the US participants was 38.6 years [standard deviation $(\mathrm{SD})=9.7$ ] and that of Indian participants was $30.7(\mathrm{SD}=9.6)$. The mean age at onset for the US participants was 20.2 years $(\mathrm{SD}=7.1)$ and that of Indian participants was $22.8(\mathrm{SD}=7.1)$. In the US sample, $46.3 \%$ of the men and $50 \%$ of the women had more than 12 years of education. In the Indian sample, $36.9 \%$ of the men and $39.1 \%$ of the wom- en had more than 12 years of education.

\section{Sex based analyses}

Age, onset age and education were not significantly different by sex in the US or the Indian sample. Additional comparisons by sex were then conducted.

\section{US sample}

Among the US patients, significant male-female differences exceeded chance predictions $(15 / 240$ variables at $\mathrm{p}=0.02$ or better, 6.25\%; detailed list in Supplementary Table 1). Following Bonferroni corrections for multiple comparisons, eight variables were significantly different (Table 2, Supplementary Table 1). SZ was the more frequent diagnosis among men $(66.6 \%)$. Among women, SZ and schizoaffective disorder were diagnosed more evenly $(50.8 \%$ vs. $49.2 \%)$. The majority of male patients did not have children $(77.8 \%)$, while proportionately more women $(47.5 \%)$ had one or more children. A higher proportion of men $(18.2 \%)$ had joined the military (71 participants). Cannabis abuse was more common among men $(73.6 \%)$ than women $(58.2 \%)$. Men were more like-

Table 1. Demographic and clinical characteristics of the samples

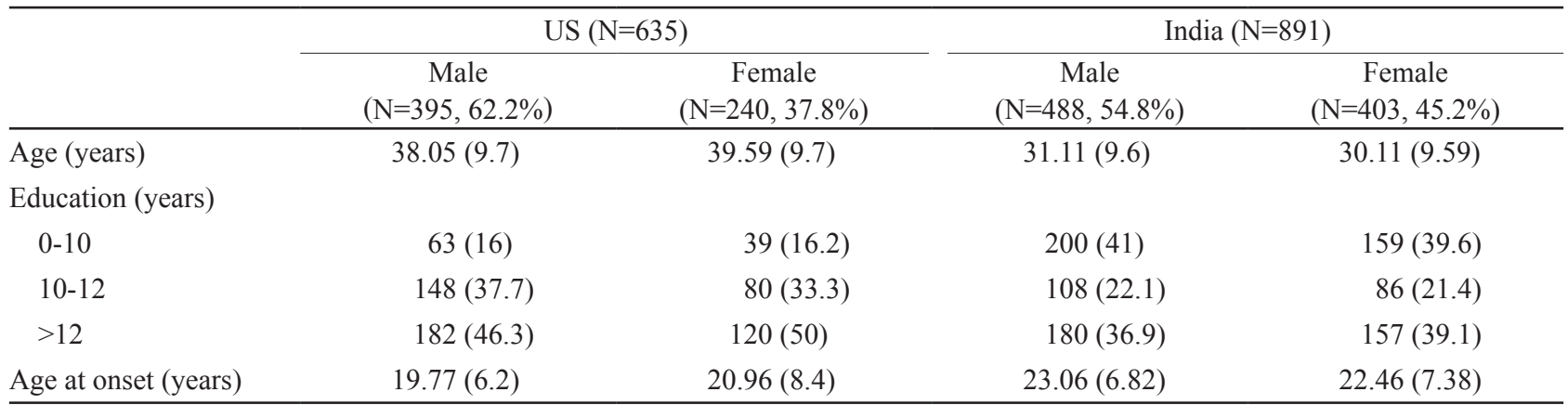

Numbers shown as means. The numbers in brackets indicate percentages for discontinuous variables or standard deviations for continuous variables

Table 2. US sample: variables with significant gender differences following corrections for multiple comparisons

\begin{tabular}{|c|c|c|c|}
\hline Demographics & Male, N (\%) & Female, N (\%) & p-value*, d.f., Chi-value \\
\hline \multicolumn{4}{|l|}{ Diagnosis } \\
\hline SZ/SZA & $263(66.6) / 132(33.4)$ & $122(50.8) / 118(49.2)$ & $0.01968,1,15.513$ \\
\hline Current marital status (ever/never) & $81(20.6) / 313(79.2)$ & $103(43.3) / 135(56.7)$ & $0.00024,1,37.108$ \\
\hline Number of living children $(0 / 1 />1)$ & $298(77.8) / 40(10.4) / 45(11.7)$ & $126(52.5) / 35(14.6) / 79(32.9)$ & $0.01224,2,19.756$ \\
\hline Ever been in military (yes/no) & $71(18.2) / 320(81.8)$ & $10(4.2) / 229(95.8)$ & $0.00024,1,25.854$ \\
\hline \multicolumn{4}{|l|}{ Drug abuse } \\
\hline Ever used marijuana (yes/no) & $285(73.6) / 102(26.4)$ & $138(58.2) / 99(41.8)$ & $0.01512,1,15.997$ \\
\hline $\begin{array}{l}\text { Ever used hallucinogens to feel good } \\
\text { or high (yes/no) }\end{array}$ & $125(35.6) / 226(64.4)$ & $39(18.2) / 175(81.8)$ & $0.00024,1,19.512$ \\
\hline \multicolumn{4}{|l|}{ Medical history } \\
\hline Thyroid/Hormonal disorders (yes/no) & $35(9) / 352(91)$ & $58(24.8) / 176(75.2)$ & $0.00024,1,28.382$ \\
\hline Migraine/Headaches (yes/no) & $58(15.3) / 321(84.7)$ & $80(34.6) / 151(65.4)$ & $0.00024,1,30.63$ \\
\hline
\end{tabular}

${ }^{*}$ p-values corrected for multiple comparisons. SZ: schizophrenia, SZA: schizoaffective disorder 
Table 3. Indian sample: variables with significant gender differences following corrections for multiple comparisons

\begin{tabular}{lccc}
\hline & Male, N (\%) & Female, N (\%) & p-value, d.f., Chi-value \\
\hline $\begin{array}{l}\text { Drug abuse: ever used marijuana } \\
\quad \text { Ever/Never }\end{array}$ & $28(5.9) / 445(94.1)$ & $2(0.5) / 386(99.5)$ & $0.00024,1,18.51$ \\
$\begin{array}{l}\text { Alcohol abuse: ever drink alcohol } \\
\quad \text { Ever/Never }\end{array}$ & $133(27.5) / 350(72.5)$ & $5(1.3) / 380(98.7)$ & $0.00024,1,110.29$ \\
$\begin{array}{l}\text { Psychosis: ever show emotions that did not fit what } \\
\text { was going on (Q58 from psychosis section, DIGS) } \\
\quad\end{array}$ & $206(42.2) / 282(57.8)$ & $219(54.9) / 180(45.1)$ & $0.048,1,14.13$ \\
$\quad$ Yes/ No & & & $0.042,4,22.3$ \\
\hline $\begin{array}{l}\text { Opcrit } \\
\text { Q1. Course disorder 1/2/3/4/5 }\end{array}$ & $29 / 39 / 63 / 37 / 308$ & $32 / 65 / 60 / 15 / 223$ & \\
\hline
\end{tabular}

Only variables that would remain significant following Bonferroni corrections are listed. *p-values corrected for multiple comparisons. 1: single episode with good recovery, 2: multiple episodes with good recovery between episodes, 3: multiple episodes with partial recovery between episodes, 4: continuous chronic illness without/deterioration, 5: continuous chronic illness with deterioration. DIGS: Diagnostic Interview for Genetic Studies

ly to be unmarried (79.2\% vs. $56.7 \%$ ). Women were more likely to report the presence of thyroid or other hormonal disorders (male : female; $9 \%: 24.8 \%$ ) or migraine headaches (male : female; $15.3 \%: 34.6 \%$ ).

\section{Indian sample}

Four variables were significantly different following Bonferroni corrections (Table 3, Supplementary Table 2). Drug or alcohol consumption was more common among men than women. Women were more frequent in the category of 'showing emotions that did not fit for what was going on' (men : women; $42.2 \%: 54.9 \%$ ). Compared to women, more men were categorized as having continuous chronic illness with deterioration (Opcrit rating scale, Q1).

\section{Stage II: Post-hoc multivariate analyses}

After completing the univariate analyses, we conducted posthoc multivariate analyses to further explore the observed differences, in the presence of significant covariates. Only Bonferoni corrected significant variables from the Indian or the US samples were included as outcome variables (Table 1-3). In the combined US and Indian samples, age, age at onset and education were included as covariates, with sex and nationality as the independent variables. We included age at onset as an index of illness severity. The following variables were not included for post-hoc analyses due to lack of sufficient sample cell sizes in one or both samples: thyroid diseases, 'ever been in military', 'ever used marijuana', 'ever used hallucinogen to feel good or high', 'ever consumed alcohol regularly'.

Sex continued to be a significant predictor for four variables: course of the disorder $[\mathrm{p}=0.00023$; OR $0.66,95 \%$ confidence interval (CI) 1.808, 1.984]; life time history of 'showing emotions that did not fit for what was going on' ( $p=$ 0.00047 ; OR $0.638,95 \%$ CI $0.496,0.821)$, marital status ( $\mathrm{p}=$ 0.0011 ; OR $0.662,95 \%$ CI $1.225,2.255)$, number of living children ( $\mathrm{p}=0.000001$; OR $0.472,95 \%$ CI $0.368,0.606)$.

\section{Discussion}

Several variables with sex related differences were noted in the US and the Indian samples, but four were noted across both samples through multivariate analyses. They include the course of the illness, history of inappropriate emotions, marital status and number of children. The consistency across very diverse settings noted for these variables likely underscores their importance in the presentation of SZ. Others have reported cross-national or ethnic variation in the course of the disorder, ${ }^{8,17}$ but the differences with regard to inappropriate emotions are novel, to our knowledge. We have previously reported on sex based differences in marital status and number of children in the USA, as well as India. ${ }^{32}$ The samples analyzed in the present study overlap with the published data, so the present results should not be considered to be replications of our earlier report. Nevertheless, the consistency in sex based procreational indices reflects an important aspect of the disorder. The lack of overlap between the US and Indian samples for several other variables requires further investigation. Multivariate analyses revealed sex by nationality interactions for several of these variables (data not shown). It is possible that they are impacted by cultural, environmental or genetic differences across the sites.

Many of the sex based differences noted in the US sample are consistent with earlier reports. Two thirds of the US male participants were diagnosed with SZ, the remaining men being diagnosed with schizoaffective disorder. Men were more likely to be unmarried, to have fewer children than women and to have served in the military. They had more hospitalizations than women. In developed countries, sex has previously been reported to be significantly associated with diagnosis ${ }^{2,21}$;

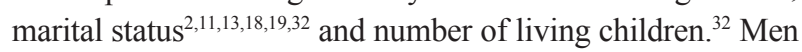
are reported to have more hospitalizations and longer hospital stays than women. ${ }^{10,11,45}$ Premenopausal women appear to experience an overall better course of the illness compared to 
men. ${ }^{26}$ The sex based differences noted in our sample are thus consistent with several prior reports. ${ }^{3,4,11,26,31,45-48}$ These differences are postulated to be due to biological differences, including hormonal changes. ${ }^{4,28,31}$ Others have suggested proteins encoded by sex chromosomes [Monoamine oxidase (MAO) or candidates gene variants ${ }^{24}$ as causal].

Our Indian sample was ascertained and evaluated in the same manner as our US sample. It was substantially larger than the US sample. However, fewer variables differed significantly in the Indian sample following correction for multiple comparisons. Some variables showed sex related differences in both samples, though they did not remain significant following Bonferoni corrections (Table 2, 3; supplementary Table 1,2). For example, migraine, as well as thyroid disorders was reported more often by women in the US sample. Thyroid disorders were also more commonly reported by Indian women, but migraine was not associated with gender in India. Thyroid disorders and migraine are more frequent among women in population based surveys, ${ }^{49-51}$ so the sex differences observed here may not be related to SZ per se. Grandiose delusions were more common among men in both samples. Chu and colleagues ${ }^{52}$ reported that men with SZ were slower, hypoactive, and grandiose, while Galdos ${ }^{53}$ did not report such associations in a UK sample.

More men than women were likely to have used alcohol at least once in the Indian sample, consistent with Indian cultural traditions. A similar difference in lifetime alcohol use was not observed in the US sample, though US male patients were more likely to have used alcohol for at least 6 months on a regular basis. In both the samples, women were more likely to rate positive for the variable, 'returned to normal self at least two months' (Q66, Psychosis section of DIGS). This is consistent with some earlier reports- Salem and Kring ${ }^{31}$ documented that men had poorer course and medication response, poorer premorbid social and intellectual functioning.

Some limitations of the present study need to be considered. Though we aimed for representative samples, neither the US nor the Indian samples were ascertained randomly. Thus, neither sample can be considered representative of patients in the US or India. As there were no exclusions based on gender, however, the gender related differences noted here are unlikely to reflect selection bias. Medications very likely impact on many of the variables listed here, and men are known to receive higher doses of medications than women. ${ }^{31}$ As accurate medication data were not available, we included age at onset in our multivariate analyses. As this variable is correlated with illness severity, we reasoned that it could function as a crude index of illness severity. In addition, we analyzed psychopathology in relation to lifetime occurrence.

\section{Conclusion}

Four variables appear to be consistently observed across both samples, after accounting for key clinical and demographic variables. Different patterns of sex related differences were observed among US and Indian patients with regard to other variables, suggesting an impact of environmental/cultural factors.

\section{REFERENCES}

1. Aleman A, Kahn RS, Selten JP. Sex differences in the risk of schizophrenia: evidence from meta-analysis. Arch Gen Psychiatry 2003;60: 565-571.

2. Castle DJ, Wessely S, Murray RM. Sex and schizophrenia: effects of diagnostic stringency, and associations with and premorbid variables. Br J Psychiatry 1993;162:658-664.

3. Iacono WG, Beiser M. Are males more likely than females to develop schizophrenia? Am J Psychiatry 1992;149:1070-1074.

4. Leung A, Chue P. Sex differences in schizophrenia, a review of the literature. Acta Psychiatr Scand Suppl 2000;401:3-38.

5. Pinals DA, Malhotra AK, Missar CD, Pickar D, Breier A. Lack of gender differences in neuroleptic response in patients with schizophrenia. Schizophr Res 1996;22:215-222.

6. Seeman MV. Gender differences in the prescribing of antipsychotic drugs. Am J Psychiatry 2004;161:1324-1333.

7. Yassa R, Jeste DV. Gender differences in tardive dyskinesia: a critical review of the literature. Schizophr Bull 1992;18:701-715.

8. Lindamer LA, Bailey A, Hawthorne W, Folsom DP, Gilmer TP, Garcia $P$, et al. Gender differences in characteristics and service use of public mental health patients with schizophrenia. Psychiatr Serv 2003;54: 1407-1409.

9. Angermeyer MC, Kühn L, Goldstein JM. Gender and the course of schizophrenia: differences in treated outcomes. Schizophr Bull 1990; 16:293-307.

10. Salokangas RK. Prognostic implications of the sex of schizophrenic patients. Br J Psychiatry 1983;142:145-151.

11. Usall J, Araya S, Ochoa S, Busquets E, Gost A, Márquez M. Gender differences in a sample of schizophrenic outpatients. Compr Psychiatry 2001;42:301-305.

12. Angermeyer MC, Kühn L. Gender differences in age at onset of schizophrenia. An overview. Eur Arch Psychiatry Neurol Sci 1988;237: 351-364.

13. Goldstein JM, Tsuang MT, Faraone SV. Gender and schizophrenia: implications for understanding the heterogeneity of the illness. Psychiatry Res 1989;28:243-253

14. Häfner H, Riecher-Rössler A, An Der Heiden W, Maurer K, Fätkenheuer B, Löffler W. Generating and testing a causal explanation of the gender difference in age at first onset of schizophrenia. Psychol Med 1993;23:925-940.

15. Usall J, Haro JM, Ochoa S, Márquez M, Araya S. Influence of gender on social outcome in schizophrenia. Acta Psychiatr Scand 2002;106: 337-342.

16. Roy MA, Maziade M, Labbé A, Merette C. Malé gender is associated with deficit schizophrenia: a meta-analysis. Schizophr Res 2001;47: 141-147.

17. Bardenstein KK, McGlashan TH. Gender differences in affective, schizoaffective, and schizophrenic disorders. A review. Schizophr Res 1990;3:159-172.

18. Opjordsmoen S. Long-term clinical outcome of schizophrenia with special reference to gender differences. Acta Psychiatr Scand 1991; 834:307-313.

19. Andia AM, Zisook S, Heaton RK, Hesselink J, Jernigan T, Kuck J, et al. Gender differences in schizophrenia. J Nerv Ment Dis 1995;183: 522-528.

20. Shtasel DL, Gur RE, Gallacher F, Heimberg C, Gur RC. Gender differences in the clinical expression of schizophrenia. Schizophr Res 
1992;7:225-231.

21. Beauchamp G, Gagnon A. Influence of diagnostic classification on gender ratio in schizophrenia - a meta-analysis of youths hospitalized for psychosis. Soc Psychiatry Psychiatr Epidemiol 2004;39:1017-1022.

22. DeLisi LE, Dauphinais ID, Hauser P. Gender differences in the brain: are they relevant to the pathogenesis of schizophrenia? Compr Psychiatry 1989;30:197-208.

23. Flor-Henry P. Influence of gender in schizophrenia as related to other psychopathological syndromes. Schizophr Bull 1990;16:211-227.

24. DeLisi LE, Crow TJ. Evidence for a sex chromosome locus for schizophrenia. Schizophr Bull 1989;15:431-440.

25. Cho JJ, Iannucci FA, Fraile M, Franco J, Alesius TN, Stefano GB. The role of the estrogen in neuroprotection: implications for neurodegenerative diseases. Neuro Endocrinol Lett 2003;24:141-147.

26. Halbreich U, Kahn LS. Hormonal aspects of schizophrenias: an overview. Psychoneuroendocrinology 2003; 28 Suppl 2:1-16.

27. Seeman MV, Lang M. The role of estrogens in schizophrenia gender differences. Schizophr Bull 1990;16:185-194.

28. Hafner H. Prevention and early intervention in schizophrenia: facts and visions. Seishin Shinkeigaku Zasshi 2002;104:1033-1054.

29. Nasser EH, Walders N, Jenkins JH. The experience of schizophrenia: what's gender got to do with it? A critical review of the current status of research on schizophrenia. Schizophr Bull 2002;28:351-362.

30. Riecher-Rössler A, Häfner H. Gender aspects in schizophrenia: bridging the border between social and biological psychiatry. Acta Psychiatr Scand Suppl 2000;407:58-62.

31. Salem JE, Kring AM. The role of gender differences in the reduction of etiologic heterogeneity in schizophrenia. Clin Psychol Rev 1998;18: 795-819.

32. Bhatia T, Franzos MA, Wood JA, Nimgaonkar VL, Deshpande SN. Gender and procreation among patients with schizophrenia. Schizophr Res 2004;68:387-394.

33. Naqvi H, Khan MM, Faizi A. Gender differences in age at onset of schizophrenia. J Coll Physicians Surg Pak 2005;156:345-348.

34. Thara R, Rajkumar S. Gender differences in schizophrenia. Results of a follow-up study from India. Schizophr Res 1992;7:65-70.

35. Venkatesh BK, Thirthalli J, Naveen MN, Kishorekumar KV, Arunachala U, Venkatasubramanian $\mathrm{G}$, et al. Sex difference in age of onset of schizophrenia: findings from a community-based study in India. World Psychiatry 2008;7:173-176.

36. Deshpande SN, Bhatia T, Wood J, Brar JS, Thelma BK, Ganguli R, et al. Evaluation of familial influences on the course and severity of schizophrenia among US and Indian cases. Soc Psychiatry Psychiatr Epidemiol 2004;39:369-374.

37. Thomas P, Mathur P, Gottesman II, Nagpal R, Nimgaonkar VL, Deshpande SN. Correlates of hallucinations in schizophrenia: A crosscultural evaluation. Schizophr Res 2007;92:41-49.

38. Deshpande SN, Mathur MN, Das SK, Bhatia T, Sharma S, Nimga- onkar VL. A Hindi version of the Diagnostic Interview for Genetic Studies. Schizophr Bull 1998;24:489-493.

39. Nurnberger JI Jr, Blehar MC, Kaufmann CA, York-Cooler C, Simpson SG, Harkavy-Friedman J, et al. Diagnostic interview for genetic studies. Rationale, unique features, and training. NIMH Genetics Initiative. Arch Gen Psychiatry 1994;51:849-859; discussion 863-864.

40. Endicott J, Spitzer RL, Fleiss JL, Cohen J. The global assessment scale. A procedure for measuring overall severity of psychiatric disturbance. Arch Gen Psychiatry 1976;33:766-771.

41. Andreasen NC. The Scale for the Assessment of Positive Symptoms (SAPS) Iowa City. Iowas: The University of Iowa; 1983.

42. Andreasen NC. The Scale for the Assessment of Positive Symptoms (SAPS) Iowa City. Iowas: The University of Iowa; 1984.

43. Kendler KS, Lieberman JA, Walsh D. The Structured Interview for Schizotypy (SIS): a preliminary report. Schizophr Bull 1989;15:559571.

44. McGuffin P, Farmer A, Harvey I. A polydiagnostic application of operational criteria in studies of psychotic illness. Development and reliability of the OPCRIT system. Arch Gen Psychiatry 1991;48:764770.

45. Usall J, Ochoa S, Araya S, Márquez M. Gender differences and outcome in schizophrenia: a 2-year follow-up study in a large community sample. Eur Psychiatry 2003;18:282-284.

46. Faraone SV, Chen WJ, Goldstein JM, Tsuang MT. Gender differences in age at onset of schizophrenia. Br J Psychiatry 1994;164:625-629.

47. Häfner H, Hambrecht M, Löffler W, Munk-Jørgensen P, RiecherRössler A. Is schizophrenia a disorder of all ages? A comparison of first episodes and early course across the life-cycle. Psychol Med 1998;28: 351-365.

48. Usall J, Ochoa S, Araya S, Gost A, Busquets E; Group NEDES. [Symptomatology and gender in schizophrenia.] Actas Esp Psiquiatr 2000; 28:219-223.

49. Kaloumenou I, Mastorakos G, Alevizaki M, Duntas LH, Mantzou E, Ladopoulos C, et al. Thyroid autoimmunity in schoolchildren in an area with long-standing iodine sufficiency: correlation with gender, pubertal stage, and maternal thyroid autoimmunity. Thyroid 2008;18:747754.

50. Shimizu T, Toriumi H, Sato H, Shibata M, Nagata E, Gotoh K, et al. Distribution and origin of TRPV1 receptor-containing nerve fibers in the dura mater of rat. Brain Res 2007;1173:84-91.

51. Uzunlulu M, Yorulmaz E, Oguz A. Prevalence of subclinical hypothyroidism in patients with metabolic syndrome. Endocr J 2007;54: 71-76.

52. Chu CC, Abi-Dargham A, Ackerman B, Cetingök M, Klein HE. Sex differences in schizophrenia. Int J Soc Psychiatry 1989;35:237-244.

53. Galdos P, van Os J. Gender, psychopathology, and development: from puberty to early adulthood. Schizophr Res 1995;14:105-112. 
Supplementary Table 1. US sample: Nominally significant sex based differences

\begin{tabular}{|c|c|c|c|c|c|}
\hline Demographics & $\mathrm{N}$ & $\begin{array}{l}\text { Sex }(\mathrm{M}, \mathrm{F}) \\
\text { frequency }\end{array}$ & $\begin{array}{c}\text { Chi-value/ } \\
\text { t-value }\end{array}$ & d.f & p-value \\
\hline Diagnosis SZ/SZA & 635 & $263 / 132,122 / 118$ & 15.513 & 1 & 0.000082 \\
\hline Current marital status (Ever/never) & 632 & $81 / 313,103 / 135$ & 37.108 & 1 & 0.000001 \\
\hline Number of children $(0 / 1 />1)$ & 623 & $298 / 40 / 45,126 / 35 / 79$ & 19.576 & 2 & 0.000051 \\
\hline Ever been in military & 630 & $71 / 320,10 / 229$ & 25.854 & 1 & 0.000001 \\
\hline \multicolumn{6}{|l|}{ Drugs } \\
\hline Ever Used marijuana & 624 & $285 / 102,138 / 99$ & 15.997 & 1 & 0.000063 \\
\hline $\begin{array}{l}\text { Ever used Hallucinogens to feel good or high or } \\
\text { to feel active or alert }\end{array}$ & 565 & $125 / 226,39 / 175$ & 19.512 & 1 & 0.00001 \\
\hline \multicolumn{6}{|l|}{ Alcohol } \\
\hline $\begin{array}{l}\text { Ever drink alcohol regularly at least once a week } \\
\text { for six months or more (Q5, Alcohol) }\end{array}$ & 578 & $156 / 206,117 / 101$ & 7.935 & 1 & 0.00485 \\
\hline $\begin{array}{l}\text { Ever get drunk that is, when your speech was slurred or } \\
\text { you were unsteady on your feet }\end{array}$ & 567 & $82 / 275,64 / 148$ & 4.493 & 1 & 0.0340 \\
\hline \multicolumn{6}{|l|}{ Medical history } \\
\hline Number of overnight hospital stay including surgery & 550 & - & 13.252 & 3 & 0.004121 \\
\hline Thyroid or other hormonal disorders & 621 & $35 / 352,58 / 176$ & 28.382 & 1 & 0.000001 \\
\hline Migraine/Head aches & 610 & $58 / 321,80 / 151$ & 30.63 & 1 & 0.000001 \\
\hline Vitamin deficiency & 615 & $365 / 16,211 / 25$ & 9.796 & 1 & 0.001749 \\
\hline \multicolumn{6}{|l|}{ Major depression } \\
\hline $\begin{array}{l}\text { Ever had a period at least one week bothered most of the day } \\
\text { feeling depressed sad down low q1 }\end{array}$ & 612 & $120 / 244,48 / 175$ & 13.509 & 1 & 0.000237 \\
\hline $\begin{array}{l}\text { Ever had a period at least one week not enjoy most things } \\
\text { usually like to do Q2 }\end{array}$ & 587 & $122 / 258,46 / 186$ & 11.244 & 1 & 0.000799 \\
\hline $\begin{array}{l}\text { If any symptoms like, loss of appetite, sleeping problems, } \\
\text { talking problems, thinking disability or guilty feeling } \\
\text { were present } \mathrm{q} 6\end{array}$ & 426 & $73 / 173,28 / 152$ & 11.456 & 1 & 0.000713 \\
\hline Seek or receive help from a doctor or other professional q23 & 422 & $49 / 193,19 / 161$ & 9.170 & 1 & 0.002460 \\
\hline
\end{tabular}

Only variables that remained significant at $\mathrm{p}=0.02$ or better are shown ( $\mathrm{p}$-values uncorrected for multiple comparisons) 
Supplementary Table 2. India sample: Nominally significant sex based differences

\begin{tabular}{|c|c|c|c|c|c|}
\hline Demographics & $\mathrm{N}$ & $\begin{array}{l}\text { Sex (Male, Female) } \\
\text { frequency }\end{array}$ & $\begin{array}{c}\text { Chi-value/ } \\
\text { t-value }\end{array}$ & d.f & p-value \\
\hline \multicolumn{6}{|l|}{ Medical history } \\
\hline Thyroid/Hormonal problems & 803 & $434 / 1,355 / 13$ & 12.694 & 1 & $0.000456^{*}$ \\
\hline Smoked cigarettes daily basis & 785 & $260 / 166,353 / 6$ & 158.38 & 1 & $0.000001^{*}$ \\
\hline \multicolumn{6}{|l|}{ Drugs, Alcohol } \\
\hline Ever used marijuana (ever/never) & 861 & $28 / 445,2 / 386$ & 18.511 & 1 & $0.000001^{*}$ \\
\hline Ever used alcohol (Q1, alcohol) (ever/never) & 868 & $133 / 350,5 / 380$ & 110.299 & 1 & $0.000001^{*}$ \\
\hline \multicolumn{6}{|l|}{ OPCRIT } \\
\hline Course disorder $(1 / 2 / 3 / 4 / 5)^{\dagger}$ & 871 & $\begin{array}{l}29 / 39 / 63 / 37 / 308 \\
32 / 65 / 60 / 15 / 223\end{array}$ & 22.295 & 4 & $0.000175^{*}$ \\
\hline \multicolumn{6}{|l|}{ Psychosis } \\
\hline Ever returned to normal self for at least two months & 864 & $334 / 141,236 / 153$ & 8.867 & 1 & $0.003106^{*}$ \\
\hline Grandiose delusions & 858 & $323 / 145,308 / 82$ & 10.84 & 1 & $0.001083^{*}$ \\
\hline Being controlled & 858 & $300 / 168,281 / 109$ & 6.148 & 1 & $0.015468^{\dagger}$ \\
\hline Thought broadcasting & 858 & $403 / 66,355 / 34$ & 5.871 & 1 & $0.018419^{\dagger}$ \\
\hline Ever show emotions that did not fit what was going on & 887 & $206 / 282,219 / 180$ & 14.129 & 1 & $0.000200^{*}$ \\
\hline $\begin{array}{l}\text { Return to feeling like your normal self for } \\
\text { at least two months }\end{array}$ & 890 & $343 / 145,246 / 156$ & 8.142 & 1 & $0.004462^{*}$ \\
\hline Number of episodes (Q67 Psychosis) & 881 & - & -2.575 & & $0.006565^{*}$ \\
\hline Longitudinal course & 888 & $\begin{array}{l}78 / 39 / 327 / 27 / 15 \\
71 / 61 / 236 / 19 / 15\end{array}$ & 13.440 & 4 & $0.009301^{*}$ \\
\hline
\end{tabular}

Only variables that remained significant at $\mathrm{p}=0.02$ or better are shown $\left({ }^{*} \mathrm{p}\right.$-values uncorrected for multiple comparisons). ${ }^{\dagger} 1:$ Single episode with good recovery, 2: Multiple episodes with good recovery between episodes, 3: Multiple episodes with partial recovery between episodes, 4: Continuous chronic illness without/deterioration, 5: Continuous chronic illness with deterioration 